\title{
Bisphosphonate-associated adverse events
}

\author{
Peter D. Papapetrou \\ Honorary Director, Second Division of Endocrinology, "Alexandra” Hospital, Athens, Greece
}

\begin{abstract}
The adverse events of the nitrogen-containing bisphosphonates are reviewed. Oral bisphosphonates (alendronate, risedronate and ibandronate), mainly used for the treatment of osteoporosis, have been associated with adverse events from the upper gastrointestinal tract, acute phase response, hypocalcaemia and secondary hyperparathyroidism, musculoskeletal pain, osteonecrosis of the jaw and ocular events. Intravenous bisphosphonates (pamidronate, ibandronate and zoledronic acid), used in oncology and for the treatment of osteoporosis, have been associated with all the above adverse events, except those from the upper gastrointestinal tract. Moreover, pamidronate and zoledronic acid have been associated with renal toxicity. Association of bisphosphonates with atrial fibrillation and atypical fractures of the femoral diaphysis remains uncertain. There are a few case reports relating bisphosphonates to cutaneous reactions, oral ulcerations, hepatitis and esophageal cancer. Generally, intravenous are more potent than oral bisphosphonates and the frequency and severity of some of the bisphosphonate-associated adverse events are dose and potency dependent.
\end{abstract}

Key words: Adverse events, Bisphosphonates intravenous, Bisphosphonates oral, Osteoporosis

\section{A. INTRODUCTION}

Bisphosphonates are widely used for the treatment of osteoporosis, Paget's disease, metastatic bone disease, multiple myeloma and hypercalcaemia of malignancy.

The intravenous bisphosphonates commonly used for the treatment of malignancies-pamidronate $(90$ $\mathrm{mg}$ infused over 2 hours), ibandronate (6 mg infused over 1 hour) and zoledronic acid (4 mg infused over

Address for correspondence:

Peter D. Papapetrou, 51 Panagiotou Street, 15669 Papagou, Athens, Greece, Tel.: 210 6536669, Fax: 2106537467 ,

E-mail: pdpap@otenet.gr

Received 10-02-09, Revised 10-03-09, Accepted 15-03-09
15 min) - are usually administered every 3-4 weeks for the rest of the patient's life. Intravenous ibandronate ( $3 \mathrm{mg}$ every three months) and zoledronic acid ( $5 \mathrm{mg}$ once-yearly) have also been approved for the treatment of osteoporosis. The orally administered nitrogen-containing bisphosphonates, alendronate (70 $\mathrm{mg}$ once-weekly), risedronate (35 mg once-weekly) and ibandronate (150 mg once-monthly) are widely used for the treatment of osteoporosis. The profiles of the adverse effects of oral and intravenous bisphosphonates differ in many aspects. Several heretofore unrecognized side effects of bisphosphonates were recently reported. In this article new and older side effects of these drugs, as well as some differences in the side effects between oral and intravenous bisphosphonates, are reviewed. 


\section{B. MECHANISM OF ACTION OF BISPHOSPHONATES}

The mechanism of action of bisphosphonates has been reviewed by Roelofs et al. ${ }^{1}$ Bisphosphonates have the ability to bind divalent ions such as $\mathrm{Ca}^{2+}$ and hence are rapidly cleared from the circulation and adsorbed into active bone mineral surfaces undergoing osteoclastic bone resorption. This results in an effective uptake of bisphosphonates into osteoclasts by endocytosis and explains their selective action on these cells. Other cell types which internalize bisphosphonates by endocytosis are osteoblasts, macrophages, epithelial and endothelial cells, circulating monocytes and also neoplastic cells such as myeloma and prostate tumor cells. ${ }^{1}$ The first-generation of non nitrogen-containing bisphosphonates, such as clodronate and etidronate, are metabolized intracellurarly to analogues of ATP. These metabolites inhibit bone resorption by inducing osteoclast apoptosis, very likely by inhibiting ATP-dependent enzymes. ${ }^{1}$ In contrast to the first-generation bisphosphonates, the nitrogen-containing bisphosphonates such as pamidronate, alendronate, risedronate, ibandronate and zoledronic acid are not metabolized to ATP analogues. They act by inhibiting Farnesyl Diphosphate (FPP) synthase, a key enzyme of the mevalonate pathway. This, among other complex biochemical changes, leads to intracellular accumulation of isopentenyl diphosphate (IPP). The inhibition of FPP synthase prevents the prenylation of small GTPases. Prenylated small GTPases are important signaling proteins and this inhibition of protein prenylation affects a variety of cell functions. The inhibition of osteoclasts by the nitrogen-containing bisphosphonates is very likely mediated by their action on the FPP synthase, which leads to protracted apoptosis of these giant cells, as was demonstrated by Weinstein et al. ${ }^{2}$ In monocytes, the accumulated IPP results in activation and proliferation of $\gamma, \delta$ T cells, triggering proinflammatory cytokine release and thus causing acute systemic inflammatory reactions. ${ }^{1,3}$

\section{ADVERSE EVENTS}

\section{Upper gastrointestinal tract adverse events}

Adverse events from the upper gastrointestinal (GI) tract associated with bisphosphonate use such as nausea, vomiting, epigastric pain and dyspepsia were reported soon after the introduction of the oral formulations of the drugs for the treatment of osteoporosis. These adverse events are due to mucosal irritation of the upper GI tract caused by the bisphosphonates. Several cases of esophagitis with esophageal erosions or ulcerations associated with the use of alendronate were reported early on through post-marketing surveillance of the drug. ${ }^{4}$ In this surveillance it was noted that patients with the more severe esophageal complications swallowed alendronate with little or no water, lay down during or shortly after ingestion of the tablet, continued to take alendronate after the onset of symptoms or had pre-existing esophageal disorders. ${ }^{4}$ Recommendations to reduce the risk of esophagitis include swallowing alendronate with 180 to $240 \mathrm{ml}$ of water on arising in the morning, remaining upright for at least 30 minutes after swallowing the tablet and until the first food of the day has been ingested and discontinuing the drug promptly if esophageal symptoms develop. ${ }^{4}$ These instructions about the correct dosing of oral bisphosphonates are included on the label of the drugs and presumably account for the later decrease in the frequency of the upper GI tract side effects of the drugs.

Bauer et $\mathrm{al}^{5}$ investigated the upper GI tract safety of alendronate in the Fracture Intervention Trial (FIT). In this large, randomized, double-blind, placebocontrolled trial, American women taking alendronate $5 \mathrm{mg} / \mathrm{d}$ or $10 \mathrm{mg} / \mathrm{d}$ for osteoporosis were followed up for 3.8 years. The overall incidence of upper GI tract adverse events was similar in the alendronate and placebo groups ( $47.5 \%$ vs $46.2 \%)$. The incidence of serious gastroduodenal events (perforations, ulcers, bleeding) was $1.6 \%$ in the alendronate group and $1.9 \%$ in the placebo group. The incidence of nonspecific upper GI complaints, such as abdominal pain, dyspepsia, nausea and vomiting, was similar in the two groups. Esophageal events occurred in $10.0 \%$ of patients in the alendronate and $9.4 \%$ in the placebo groups. Non-reflux esophagitis tended to be, though not significantly, more common in the alendronate group $(0.7 \%)$ than in the placebo group $(0.4 \%)$. Alendronate use was not associated with a significant increase in upper GI tract events among patients at increased risk for these events (women aged 
$>75$ years, with previous upper GI tract disease or using non-steroidal anti-inflammatory drugs). ${ }^{5}$ Cryer et $\mathrm{al}^{6}$ also found that alendronate $70 \mathrm{mg}$ once-weekly, used concomitantly with non-steroidal anti-inflammatory drugs, did not increase upper GI adverse events relative to placebo over three months. In a multi-center, 3-month, randomized, double-blind, placebo-controlled study by Greenspan et al, ${ }^{7}$ the tolerability of once-weekly alendromate was evaluated in American patients with osteoporosis. A total of $11 \%$ of the alendronate patients and $13 \%$ of the placebo patients reported upper GI tract adverse events. Discontinuations due to drug-related upper GI tract events occurred in 3\% of alendronate patients and $1 \%$ of placebo patients. The differences between the treatment groups for both these end points of the study were not significant. ${ }^{7}$ The multi-center study by Eisman et $\mathrm{al}^{8}$ included patients from Europe, the Americas, Africa and Asia-Pacific and was similar in design to the study of Greenspan et al. ${ }^{7}$ The authors of these studies ${ }^{7,8}$ concluded that alendronate $70 \mathrm{mg}$ administered once-weekly to women and men with osteoporosis has an upper GI and overall tolerability profile similar to that of placebo.

Regarding the association of bisphosphonate use with upper GI tract adverse events, Cryer and Bauer ${ }^{9}$ reviewed the evidence originating from animal and laboratory studies, epidemiological studies, endoscopy trials and randomized controlled trials. They concluded that the evidence from randomized controlled trials suggests little or no increase in the risk of upper GI tract problems if bisphosphonates are administered properly. The evidence suggests that many upper GI tract adverse events reported during therapy with bisphosphonates may reflect a high background incidence of upper GI tract complaints and an increased sensitivity to detection rather than a causal relationship to therapy. ${ }^{9}$ Risedronate and ibandronate seem to have a GI tolerability similar to that of alendronate. ${ }^{9,10}$

Current evidence, as presented above, should be reassuring to practitioners and patients in that the use of oral bisphosphonates for treatment of osteoporosis does not increase the likelihood of upper GI adverse events on condition that the patients adhere to the rules of correct dosing and mode of intake of these drugs. With regard to upper GI tract safety, women were excluded from participating in the FIT study ${ }^{5}$ if they had had upper GI tract bleeding within the past five years requiring hospitalization or transfusion; documented recurrent or recent ulcer disease (two episodes in the preceding five years or one episode in the preceding 12 months); experienced esophageal or gastric varices; or used medication daily for dyspepsia. ${ }^{5}$ Patients with disorders of esophageal motility, such as stricture or achalasia, were also excluded from another study. ${ }^{7}$ Therefore, these exclusion criteria may be considered as contraindications for the oral bisphosphonates. In these trials, ${ }^{5,7}$ women with past or current evidence of other upper GI tract diseases (hiatal hernia, esophageal reflux, esophagitis and heartburn) were eligible for participation in the trial. Active reflux or non-reflux esophagitis are not currently considered a contraindication for oral bisphosphonates, although this condition may sometimes be a complicated problem. Esophageal reflux is a common disturbance affecting about $20 \%$ of the general population ${ }^{11}$ and can result in Barrett's esophagus, which predisposes to the development of adenocarcinoma of the esophagus. Barrett's esophagus should be a contraindication for bisphosphonates.

\section{Renal toxicity}

The earliest clinical use of a bisphosphonate (etidronate) was for the treatment of Paget's disease and dates back to $1971 .^{12}$ Subsequently, with the use of intravenous bisphosphonates (etidronate, clodronate) for the treatment of malignant hypercalcaemia due to osteolytic tumor-induced bone disease, ${ }^{12}$ several cases of renal failure were reported. ${ }^{13}$ A possible mechanism of the renal toxicity was considered at that time to be the strong affinity of the bisphosphonates for metal ions (calcium included) and their tendency to form soluble or insoluble complexes and aggregates with metal ions, notably when large amounts of the drugs were infused rapidly. ${ }^{12}$ These aggregates could be held back in the kidney and cause renal injury. ${ }^{12}$ This theory, however, is not supported in the recent literature and the mechanism of the renal toxicity of bisphosphonates remains largely unknown.

Many cases of renal toxicity were reported with the newer intravenous bisphosphonates, pamidronate and zoledronic acid, ${ }^{14,15}$ but not with ibandronate, ${ }^{16}$ used in patients with malignant disease. Patterns of 
nephrotoxicity with these drugs include toxic acute tubular necrosis and collapsing focal segmental glomerulosclerosis. ${ }^{17}$ The renal toxicity of the intravenous bisphosphonates used in patients with malignant diseases involving bone is probably enhanced by risk factors for kidney function which may be present in these patients: pre-existing Chronic Kidney Disease (CKD), multiple myeloma, hypercalcaemia, hypertension, diabetes mellitus, advanced age, chemotherapy or previous treatment with a bisphosphonate. ${ }^{16,18}$ Important factors which may increase renal toxicity of the intravenous bisphosphonates are higher dose, shorter infusion times or dose interval lower than recommended. ${ }^{16,19}$ The total dose of the drug which has been administered during a long-term treatment may also play a role because of its probable cumulative effect. ${ }^{20}$

There is no evidence till now that oral bisphosphonates, as they are used for treatment of osteoporosis, have been associated with significant renal toxicity. However, this may be an underestimation because many of the trials on the efficacy and safety of the bisphosphonates for the treatment of osteoporosis excluded patients with severe CKD. Thus, based on the FDA-approved labeling, which recommends that bisphosphonates should be used with caution in patients with creatinine clearance less than 30 $\mathrm{ml} / \mathrm{min}$, clinicians probably were not treating with bisphosphonates patients with pre-existing CKD who may be more susceptible to renal injury by these drugs. Therefore, there is uncertainty as to how the clinician should evaluate the renal function of a patient candidate for treatment with a bisphosphonate and about the management of the patient with CKD.

Renal function declines with advancing age. ${ }^{21,22}$ Renal function is not accurately assessed by serum creatinine measurements in older adults and measurement of the creatinine clearance is recommended for this purpose using either the Cockcoft-Gault (C-G) formula or the Modification of Diet in Renal Disease (MDRD) equation. ${ }^{20,21}$ Jassal et $\mathrm{al}^{22}$ reported that $48.8 \%$ of healthy seniors had $30-59 \mathrm{ml} / \mathrm{min} / 1.73 \mathrm{~m}^{2}$ creatinine clearance calculated by the $\mathrm{C}-\mathrm{G}$ formula, $2.7 \%$ had $<30 \mathrm{ml} / \mathrm{min} / 1.73 \mathrm{~m}^{2}$ and only $5.5 \%$ of these older community-dwelling persons had values $>90 \mathrm{ml} / \mathrm{min} / 1.73 \mathrm{~m}^{2}$. There was a significant linear correlation between creatinine clearance by $\mathrm{C}-\mathrm{G}$ and hip BMD. Klawansky et $\mathrm{al}^{21}$ found that $24 \%$ of women with osteoporosis (ages 20-80+) had severe renal compromise (creatinine clearance by the $\mathrm{C}-\mathrm{G}$ formula $<35 \mathrm{ml} / \mathrm{min}$ ). For ages $80+$ the proportion rises to $54 \%$. In women with osteopenia (ages $80+$ ) the prevalence of severe renal compromise was $37 \%$. Thus, a substantial proportion of candidates for treatment of osteoporosis or osteopenia have significant renal function compromise. ${ }^{21}$

Renal failure has been reported after the use of intravenous bisphosphonates ${ }^{15}$ and therefore intravenous bisphosphonates should be used with caution for the treatment of patients with osteoporosis, who have compromised renal function. ${ }^{21}$ Oral risedronate proved to be safe for the treatment of osteoporosis in patients with compromised renal function in one study. ${ }^{23}$ Oral bisphosphonates are not associated with significant nephrotoxicity ${ }^{17}$ although there have been exceptions to this rule. ${ }^{24}$

Calculated creatinine clearance is essential for the assessment of renal function in older persons with osteoporosis not only at baseline but also during treatment with bisphosphonates.

\section{Ocular adverse events}

The most common ocular side effect of bisphosphonates is nonspecific conjunctivitis, ${ }^{25}$ which usually improves without specific therapy and despite continuing treatment with a bisphosphonate. Rarely, treatment with a non-steroidal anti-inflammatory eye drop is required. ${ }^{25} \mathrm{~A}$ few cases of other ocular side effects such as eyelid edema, optic or retrobulbar neuritis, periorbital edema, cranial nerve palsy and ptosis have been reported. ${ }^{25}$ Uveitis and scleritis are the most serious ocular side effects of bisphosphonate therapy and require the discontinuation of bisphosphonate treatment. ${ }^{25,26}$ Several reported cases of uveitis and scleritis which occurred during therapy with bisphosphonates may be classified as "certain" side effects of the bisphosphonates because they fulfilled the criteria of the WHO Causality Guide of Suspected Adverse Reactions: $:^{25}$ temporal relationship to bisphosphonate therapy, absence of concurrent disease predisposing to these adverse events and positive tests at dechallenge and rechallenge. ${ }^{25}$ Fraunfelder et $a \mathrm{al},{ }^{25}$ after reviewing the inflammatory ocular side effects (scleritis and uveitis) caused by intravenous 
pamidronate disodium, remarked that scleritis patients had an associated acute phase reaction (fever and influenza-like symptoms) which often occurs in patients treated with pamidronate. Therefore, ocular inflammation may represent a localized manifestation of a systemic adverse reaction to the drug. One case of posterior scleritis ${ }^{27}$ and two cases of anterior uveitis ${ }^{28,29}$ complicating treatment with zoledronic acid have been reported. In two patients, alendronate was associated with scleritis, ${ }^{30,31}$ which was confirmed by a positive rechallenge test. Three more cases of scleritis $^{32}$ and one case of anterior uveitis ${ }^{33}$ occurred during treatment with alendronate and one case of uveitis with clodronate. ${ }^{34}$

French and $\mathrm{Margo}^{26}$ determined the 6-month rates of newly diagnosed uveitis/scleritis following dispensing of bisphosphonates in a large veteran cohort (85\% of patients received oral alendronate, $70 \mathrm{mg} / \mathrm{wk}$ ). There were 7.9 new cases of uveitis/scleritis per 10,000 individuals with a newly dispensed bisphosphonate that occurred within six months. The relative risk of uveitis/scleritis for six months was 1.23 (95\% CI 0.85 to 1.79) compared to veterans not exposed to bisphosphonates. There was no significant difference in the rates of uveitis/scleritis between users and non-users of bisphosphonates, nor between oral or parenteral use of bisphosphonates. In this study, nearly $43 \%$ of patients with uveitis/scleritis after bisphosphonates had a systemic condition commonly associated with uveitis/scleritis. According to this study, the serious ocular side effects of bisphosphonates (scleritis and uveitis) seemed to be rare and were observed 1-146 days (mean 70 days, median $=45$ days) after the initiation of bisphosphonate therapy; these side effects tended to occur earlier with intravenous compared to oral bisphosphonates. ${ }^{26}$ In the British observational study $^{35}$ a cohort of 13,643 patients treated with risedronate were followed up for 18 months. Nineteen ocular events were assessed as possibly or probably related to risedronate (dry eye: 6 , sore eye: 5 , and conjunctivitis: 3). As discussed by French and Margo, ${ }^{26}$ the frequency of uveitis/scleritis in the British study ${ }^{35}$ was one fifth of that found in their study. A possible explanation is that in the study of Aurich-Barrera et $\mathrm{al}^{35}$ the patients were examined only by general practitioners and thus some cases of severe ocular inflammation possibly were not detected because of direct referral to an ophthalmologist. ${ }^{26}$

The most common ocular adverse reaction of therapy with bisphosphonates is nonspecific conjunctivitis which usually is self-limited. It is quite possible that some cases of conjunctivitis of unidentified cause may be due to bisphosphonates, which are an ingredient of almost every soap on the market. The frequency of severe ocular inflammation (scleritis and uveitis) is generally small and not significantly increased in bisphosphonate users compared to nonusers. ${ }^{26}$ Diseases known to be associated with scleritis and uveitis are the following: ankylosing spondylitis, Behcet syndrome, psoriasis, Reiter syndrome, inflammatory bowel disease, polychondritis, Wegener granulomatosis, rheumatoid arthritis, systemic lupus erythymatosus, sarcoidosis and syphilis. ${ }^{26}$ It is possible, therefore, that uveitis or scleritis in some cases might be secondary to systemic disease or some drugs such as rifabutin, trimethoprim-sulfamethoxazole, diethylcarbamazine, metipranolol and cidovir ${ }^{26}$ with bisphosphonates playing the role of a precipitating factor. Practitioners should probably prescribe bisphosphonates with caution to patients suffering from these disease entities or taking the drugs mentioned above. The management of patients with ocular side effects from pamidronate proposed by Fraunfelder et $\mathrm{al}^{25}$ is as follows: Decrease in vision or ocular pain requires examination by an ophthalmologist. Bilateral anterior uveitis or, rarely, posterior or bilateral uveitis may occur and can vary markedly in severity. Many cases require intensive topical ocular or systemic medication. In some instances, the drug may need to be discontinued for the uveitis to resolve. Episcleritis may require topical ocular medication; however, pamidronate may be continued. In Fraunfelder's series of patients, ${ }^{25}$ for the scleritis to resolve, even on full pertinent therapy, the intravenous pamidronate had to be discontinued.

\section{Acute phase response}

Intravenous nitrogen-containing bisphosphonates are known to cause an adverse event resembling the Acute Phase Response (AFR). ${ }^{36}$ Clinically, this systemic reaction is characterized by fever, sometimes with rigors, and influenza-like symptoms such as fatigue, malaise, myalgia, arthralgia and bone pain..$^{36,37}$ This bisposphonate-induced AFR is dose-dependent, 
occurs mainly after the first infusion of a nitrogencontaining bisphosphonate in bisphosphonate naive patients and is rare in subsequent infusions of the drug. ${ }^{36,37}$ The AFR is maximally expressed 28-36 hours of IV administration of nitrogen-containing bisphosphonates and subsides 2-3 days later despite continuous treatment. ${ }^{36}$ Fever, malaise and myalgia have been reported in 30-35\% of patients receiving an initial dose of an intravenous nitrogen-containing bisphosphonate. ${ }^{37}$ However, in a group of women with a history of breast cancer, who were treated with zoledronic acid for osteoporosis secondary to aromatase inhibitor treatment, the incidence of these complaints was much higher, i.e. about $70 \% .{ }^{38}$ Intravenously administered nitrogen-containing bisphosphonstes (pamidronate, zoledronic acid and ibandronate) are known to cause a typical systemic AFR. Mild to moderate AFR may also occur with the initial exposure to once-weekly or once-monthly doses of oral bisphosphonates, that is, more often than with the daily formulations of the drugs. ${ }^{39}$ This type of reaction has not been observed with non nitrogencontaining bisphosphonates (etidronate, clordronate and tiludronate). ${ }^{37}$

The bisphosphonate-induced AFR is mediated by interleukin $6,{ }^{40}$ tumor necrosis factor $\alpha$ and other proinflammatory cytokines released by receptor-activated $\gamma \delta$ T cells and macrophages. ${ }^{37,41}$ The activation of $\gamma \delta \mathrm{T}$ cells can be inhibited by statins in vitro, ${ }^{41}$ although atorvastatin was ineffective on AFR following bisphosphonate infusion in children. ${ }^{42}$ The bisphosphonate-induced AFR is usually benign and self-limited and can be treated with antipyretics.

\section{Hypocalcaemia and secondary hyperparathyroidism}

Nitrogen-containing bisphosphonates are potent inhibitors of osteoclastic bone resorption. As a result of this effect, six weeks after starting alendronate therapy, serum calcium and phosphorus decrease and intact Parathyroid Hormone (PTH) significantly increase in a dose-dependant fashion. Calciuria and phosphaturia also decrease. ${ }^{43}$ The increased PTH antagonizes the effect of bisphosphonates in bone and conserves calcium by increasing tubular reabsorption of calcium in the kidneys and by stimulating the kidneys to produce 1,25-dihydroxyvitamin $\mathrm{D}$. Thus, under normal conditions, bisphosphonate-induced hypocalcaemia often subsides despite continued bisphosphonate therapy; symptomatic hypocalcaemia seems to be uncommon after oral bisphosphonate treatment and usually occurs weeks after the start of treatment. The more potent intravenous bisphosphonates may cause symptomatic hypocalcaemia more often than oral bisphosphonates, usually within days after the bisphosphonate infusion. Thus, symptomatic hypocalcaemia and hypomagnesemia occurred in $8 \%$ of patients with various malignancies treated with zoledronic acid despite prophylactic administration of vitamin $\mathrm{D}$ and calcium supplements. ${ }^{44}$ Risk factors for severe bisphosphonate-induced hypocalcaemia are pre-existing hypoparathyroidism, ${ }^{45,46}$ parathyroid dysfunction during thyroidectomy in a patient receiving chronic bisphosphonate therapy, ${ }^{47}$ vitamin D deficiency ${ }^{46,48}$ and renal failure. ${ }^{44,49}$ The bisphosphonate-induced hypocalcaemia and secondary hyperparathyroidism can be avoided or attenuated by the administration of adequate vitamin $\mathrm{D}$ and calcium supplements, starting about two weeks before the administration of the bisphosphonate. Berruti et $\mathrm{al}^{50}$ emphasized the need to treat effectively the secondary hyperparathyroidism in cancer patients because of the ability of high PTH to promote tumor growth.

\section{Musculoskeletal pain}

An alert by the Food and Drug Administration (FDA) on Jan. 7, 2008, stated the following: "There is a possibility of severe and sometimes incapacitating bone, joint, and/or muscle (musculoskeletal) pain in patients taking bisphosphonates. The severe musculoskeletal pain may occur within days, months or years after starting a bisphosphonate. Some patients have reported complete relief of symptoms after discontinuing the bisphosphonate, whereas others have reported slow or incomplete resolution. This severe musculoskeletal pain is in contrast to the acute phase response characterized by fever, chills, bone pain, myalgias and arthralgias that sometimes accompany initial administration of intravenous bisphosphonates and may occur with initial exposure to once-weekly or once-monthly doses of oral bisphosphonates. The symptoms related to the acute phase response tend to resolve within several days with continuing drug use". ${ }^{51}$ Between 1995 and 2002, the FDA received reports of severe bone, joint and/or muscle pain that 
developed in 112 women and four men after starting alendronate therapy. Pain affected bones, joints and muscles all over the body and was sometimes migratory. It was often described as "severe, extreme, disabling or incapacitating". The doses of alendronate were $5 \mathrm{mg} / \mathrm{d}(4 \%), 10 \mathrm{mg} / \mathrm{d}$ (74\%), 20 to $35 \mathrm{mg} / \mathrm{d}(4 \%)$ and $70 \mathrm{mg} / \mathrm{wk}(18 \%)$. The onset of pain after starting alendronate therapy ranged from same day to 52 months (mean $=91$ days, median $=14$ days). The FDA received six reports of severe bone, joint or muscle pain for risedronate. ${ }^{52}$ Bock et $\mathrm{al}^{53}$ studied the occurrence of musculoskeletal events in a large cohort of patients with osteoporosis who were treated with alendronate or risedronate daily or once-weekly. Only events starting within 48 hours after initiating bisphosphonate therapy and without any other evident cause were evaluated. No patient treated with alendronate $10 \mathrm{mg} / \mathrm{d}$ or risedronate $5 \mathrm{mg} / \mathrm{d}$ experienced significant musculoskeletal events. In contrast, $20 \%$ of patients treated initially with alendronate $70 \mathrm{mg} / \mathrm{wk}$ and $25 \%$ of patients treated initially with risedronate $35 \mathrm{mg} / \mathrm{wk}$ experienced events such as arthralgia (12.6\%), back pain $(9.1 \%)$, myalgia $(4.2 \%)$, bone pain $(4.2 \%)$, chest pain $(1.8 \%)$ and fever (1.2\%). Remarkably, none of the patients who were initially treated with daily bisphosphonate reported any musculoskeletal event when they were changed later to a once-weekly regimen. The authors suggested that pretreatment with a daily dose of bisphosphosnate for about two weeks before changing to the once-weekly regimen may desensitize the patients to musculoskeletal adverse events. ${ }^{53}$ It is very likely that the oral bisphosphonate-associated musculoskeletal adverse events reported by Bock et $\mathrm{a}^{53}$ occurred in the setting of an otherwise moderate acute phase reaction, in contrast to the severe bone, joint and muscle pain reported by the FDA, potentially unrelated to systemic acute phase reaction. ${ }^{51,52}$

The pathological basis of the delayed painful bisphosphonate-associated adverse events remains undetermined in most cases..$^{51,52}$ Several cases of bisphosphonste-associated synovitis, confirmed by positive rechallenge testing, were reported. ${ }^{54,55} \mathrm{~A}$ case of acute polyarthritis and myalgia with positive rechallenge testing occurred 12 hours after the first ingestion of alendronate $70 \mathrm{mg} .{ }^{56}$ Severe vitamin $\mathrm{D}$ deficiency, with 25-hydroxyvitamin D levels less than $20 \mathrm{nmol} / \mathrm{L}$, is not uncommon in elderly patients with osteoporosis and can lead to clinical osteomalacia with severe musculoskeletal pain involving the lower back, pelvis, upper legs and ribs. ${ }^{57}$ Failure to prescribe adequate vitamin $\mathrm{D}$ and calcium supplements along with the bisphosphonate or the patient's non-compliance with the supplements may cause clinical osteomalacia during bisphosphonate therapy for osteoporosis. A hypothetical mechanism of bone pain associated with bisphosphonate treatment may be the following: in some cases of bisphosphonateinduced secondary hyperparathyroidism ${ }^{43}$ there may be a relatively smaller reduction of bone turnover caused by the bisphosphonate because of the antagonistic effect of the high PTH. In such cases, bone turnover higher than expected from treatment with a bisphosphonate unopposed by a high PTH may lead to relatively higher bone uptake of bisphosphonate and higher than average concentration of the drug in the bone microenvironment. This in turn may result in a localized, relatively increased bisphosphonate-induced production of interleukin- 6 and other proinflammatory cytokines ${ }^{41}$ and an inflammatory reaction confined to bones. On the other hand, the high PTH in secondary hyperparathyroidism is known to cause elevated interleukin- 6 levels ${ }^{58}$ and thus higher bisphosponate concentration in bone, and high PTH may have a synergistic effect in increased production of interleukin-6.

\section{Osteonecrosis of the jaw}

In 2002, the FDA received reports of several patients with cancer, treated with the intravenous bisphosphonate zoledronic acid, who developed osteonecrosis of the jaw (ONJ) ${ }^{59}$ In the following year, Marx $^{60}$ reported on a series of 36 patients with ONJ who were treated with pamidronate or zoledronic acid. A second report in 2004 by Ruggiero et al $^{61}$ comprised 63 patients with ONJ, of whom 56 had received intravenous bisphosphonates for cancer, and seven were treated with oral bisphosphonates for osteoporosis. In the report by Bamias et al, ${ }^{62}$ among 252 patients with various malignancies treated with bisphosphonates 17 (6.7\%) developed ONJ. The incidence of ONJ increased with time of exposure to the drugs from $1.5 \%$ among patients treated for four to 12 months, to $7.7 \%$ for treatment of 37 to 48 months. ${ }^{62}$ The association of $\mathrm{ONJ}$ with bisphosphonate therapy is discussed in a report of a task force of the American 
Society for Bone and Mineral Research. ${ }^{63}$ The task force defined $\mathrm{ONJ}$ as the presence of exposed bone in the maxillofacial region that did not heal within eight weeks after identification by a health care provider. The total number of reported cases of bisphosphonate-associated $\mathrm{ONJ}$ in patients with osteoporosis or Paget's disease was 64 (57 cases that occurred in association with treatment for osteoporosis and seven cases that occurred in association with treatment of Paget's disease). The risk of ONJ associated with oral bisphosphonate therapy for osteoporosis or Paget's disease was estimated to range between 1/10,000 and $1 / 100,000$ patient-treatment years, although the true incidence may be higher. The risk of ONJ in patients with cancer treated with high doses of intravenous bisphosphonates is in the range of $1-10$ per 100 patients (depending on duration of therapy). ${ }^{63}$ The incidence of ONJ in the general population or in untreated patients with osteoporosis is not known. Among 368 reported cases of bisphosphonate-associated ONJ, the disease affected the mandible in $65 \%$, the maxilla in $26 \%$ and both sites in $9 \%$ of the cases. One third of the cases were painless. Sixty percent of cases occurred after tooth extraction or other oral surgery and the remaining spontaneously. ${ }^{64}$ The risk factors specific to ONJ include head and neck radiotherapy (resulting in so-called osteoradionecrosis), periodontal disease, dental procedures involving bone surgery, edentulous regions and trauma from poorly fitting dentures. Additional risk factors in cancer patients include the underlying malignancy, chemotherapy, corticosteroids and systemic or regional infection. Pancytopenia, secondary to cancer and/or cancer treatment is a risk for infection and osteomyelitis. Vascular insufficiency due to thrombosis caused by coagulopathies has been associated with $\mathrm{ONJ}{ }^{65}$ Drug-related risk factors include the potency of the particular bisphosphonate-the intravenous bisphosphonates zoledronic acid and pamidronate being more potent than the oral bisphosphonates-and the longer duration of therapy. Patients with a history of inflammatory dental disease, e.g. periodontal and dental abscesses, have a seven-fold increased risk for developing ONJ. Diabetes, smoking, alcohol use and poor oral hygiene are thought to be risk factors for ONJ ${ }^{66}$ The diagnosis of ONJ is made by visual inspection. ${ }^{65}$ Early identification of ONJ may be achieved by bone imaging techniques. ${ }^{63}$
Potential preventive measures for bisphosphonaterelated ONJ include: a) a routine clinical dental examination before initiating bisphosphonate therapy and, if possible, postponing the bisphosphonate therapy until the dental treatment has been carried out; ${ }^{65,66}$ b) discontinuation of oral bisphosphonates in asymptomatic patients, if systemic conditions permit, for a period of three months prior to and three months following elective invasive dental surgery; c) specific treatments for patients with established diagnosis of ONJ. ${ }^{66,67}$

The risk of developing ONJ associated with oral bisphosphonates, while exceedingly small, appears to increase when the duration of therapy exceeds three years. This time-frame may be shortened in the presence of certain comorbidities, such as chronic corticosteroid use. ${ }^{66}$

Marx et $\mathrm{al}^{67}$ found that serum type 1 collagen C-terminal telopeptide (CTX) was related to the risk for ONJ. Thus, patients with CTX values less than $100 \mathrm{pg} / \mathrm{ml}$ had high risk for ONJ, patients with values of CTX between $100 \mathrm{pg} / \mathrm{ml}$ and $150 \mathrm{pg} / \mathrm{ml}$ had moderate risk and patients with CTX values above $150 \mathrm{pg} / \mathrm{ml}$ had minimal risk. Therefore, the authors suggested discontinuing the bisphosphonate and allowing the bone turnover to recover as indicated by CTX level above $150 \mathrm{pg} / \mathrm{ml}$. This constitutes a useful guideline as to when oral surgical procedures can be accomplished with the least risk.

A considerable body of literature on ONJ associated with bisphosphonate therapy has been accumulated consisting mainly of case reports or case reports series and reviews. Despite the extensive publicity, there is still controversy about bisphosphonates as causative factors for ONJ. In cancer patients treated with intravenous bisphosphonates, the cause of ONJ is uncertain because of the coexistence of several confounding risk factors for ONJ. In patients with osteoporosis treated with oral bisphosphonates, ONJ is rare and skepticism about the potential association between oral bisphosphonate use and ONJ has been expressed. ${ }^{68,69}$ Historical evidence that bisphosphonates can be a cause of ONJ was provided recently by Marx. ${ }^{70}$ Between 1858 and 1906, there was an epidemic of ONJ named "phossy jaw" among workers in match-making factories who inhaled fumes 
of "yellow phosphorus". Marx points out that yellow phosphorus can react in the human body with $\mathrm{H}_{2} \mathrm{O}, \mathrm{CO}_{2}$ and amino acids such as lysine; as a result, bisphosphonates, almost identical to alendronate and pamidronate, are formed. ${ }^{70}$ The mechanism by which bisphosphonates may cause ONJ remains unclear. Ardine et $\mathrm{al}^{71}$ reported that patients with bisphosphonate-associated ONJ had persistently higher PTH levels compared to controls without ONJ and they suggested that high PTH may be involved in the pathogenesis of ONJ. Evidence against this theory is that in patients with primary hyperparathyroidism and elevated PTH, lesions in the oral cavity include reduced radicular lamina dura, reduced interdental alveolar bone density and reduced cortical bone at the gonial index, ${ }^{72}$ whereas the bisphosphonate-associated ONJ is characterized by osteopetrosis-like osseous sclerosis with thickening of the lamina dura and of the alveolar crest and sclerosis of the alveolar margin. ${ }^{73}$

\section{Atrial fibrillation}

The first indication that intravenous bisphosphonate zoledronic acid may cause atrial fibrillation came about during the randomized placebo-controlled trial (RCT) Health Outcomes and Reduced Incidence with Zoledronic Acid Once Yearly (HORIZON) Pivotal Fracture Trial. ${ }^{74}$ Patients who received the active drug had a higher frequency of episodes of severe atrial fibrillation compared to patients treated with placebo, although the frequency of all cases of atrial fibrillation was not different between the two groups. Severe atrial fibrillation was characterized as an episode of atrial fibrillation necessitating admission to hospital or being life-threatening or causing morbidity. After these findings, some of the authors of the RCT Fracture Intervention Trial ${ }^{75}$ analyzed retrospectively the data of the study on the occurrence of atrial fibrillation during treatment with oral alendronate for postmenopausal osteoporosis. The analysis ${ }^{76}$ showed a trend towards increased frequency of severe atrial fibrillation in alendronate treated subjects compared to those treated with placebo (RR 1.51 with $95 \%$ CI 0.97 to 2.40 ), although the difference was not significant $(\mathrm{p}=0.07)$. The frequency of all the cases of atrial fibrillation was not different between alendronate and placebo treated patients. However, a later HORIZON Recurrent Fracture Trial failed to show any difference in the frequency of severe or all cases of atrial fibrillation between zoledronic acid and placebo treated patients. ${ }^{77}$ Furthermore, analysis of the data from the risedronate RCT did not show any difference in atrial fibrillation frequency between active drug and placebo treated patients. ${ }^{78}$ Two recent case-control studies investigated whether patients who presented with atrial fibrillation were treated more often with bisphosphonates at any time ${ }^{79}$ or currently ${ }^{80}$ compared to control patients without atrial fibrillation. In an American study,$^{79}$ a group of 719 women with atrial fibrillation was compared to a group of 966 without atrial fibrillation. In the atrial fibrillation group $6.5 \%$ of the women were treated with alendromate at any time, compared to $4.1 \%$ of the women without atrial fibrillation $(p=0.03)$. Thus, the risk of atrial fibrillation was greater among the alendronate users than among the women who never used this drug (odds ratio 1.86, 95\% CI 1.09 to 3.15). In contrast, the Danish study found that the use of bisphosphonates does not increase the risk of atrial fibrillation; ${ }^{80}$ the records of 13,586 women with a history of atrial fibrillation or flutter were surveyed and compared with 68,054 control women without these cardiac complications. In this study, ${ }^{80} 3.2 \%$ of the women with atrial fibrillation or flutter and $2.9 \%$ of the control women were taking a bisphosphonate (etidronate or alendronate). The relative risk of atrial fibrillation was 0.95 (95\% CI 0.84 to 1.07).

The fact that in two trials ${ }^{74,76}$ only the frequency of severe and not of all cases of atrial fibrillation was increased by bisphosphonate therapy may indicate that bisphosphonates aggravate atrial fibrillation in patients predisposed to it from other causes. Thus, until the probable association of bisphosphonate therapy and atrial fibrillation is prospectively investigated, clinicians should be cautious in prescribing bisphosphonates for patients with a history of atrial fibrillation or a predisposition to develop atrial fibrillation. It must be mentioned that on November 12, 2008, the FDA announced that a review of the clinical trials showed no clear relationship between bisphosphonate treatment and atrial fibrillation (serious or non-serious) and the FDA's MedWatch recommended that healthcare professionals should therefore not alter their prescribing patterns for bisphosphonates and the patients should not stop taking their bisphosphonate 
medication..$^{81}$

\section{Atypical fractures of the femoral diaphysis}

In 2005, Odvina et al ${ }^{82}$ reported nine patients on long-term (3-8y) treatment with alendronate who suffered unusual, low-energy, non-spinal fractures. Five of these patients sustained femoral shaft fractures (two of them bilaterally). Bone biopsies in these patients showed excessive suppression of bone turnover reminiscent of adynamic bone, which presumably accounted for increased bone fragility resulting in atypical fractures. Six of the nine patients displayed either delayed or absent fracture healing. Three similar patients on long-term alendronate therapy with severely suppressed bone turnover and metadiaphysial femoral stress fractures were reported recently by Visekruna et al ${ }^{83}$ These authors speculated that, since femoral shaft fractures are rare among bisphosphonate users, the patients suffering from these fractures may have osteoclasts genetically susceptible to over-suppression by the bisphosphonates. ${ }^{83}$ Goh et $\mathrm{al}^{84}$ in a case-control study identified retrospectively 13 women with low-energy subtrochanteric fractures of whom nine were on long-term (2.5-5 y) alendronate therapy and four were not. Five of the patients on alendronate had prodromal pain in the affected thigh for several months preceding the fracture. In six patients cortical hypertrophy was identified in the subtrochanteric region of the femur, whereas in three patients a similar hypertrophy could be seen in the contralateral femur. In another retrospective case-control study, ${ }^{85}$ 70 aged patients were identified of whom 50 with a subtrochanteric and 20 with a femoral shaft fracture. Twenty-five ( $36 \%$ ) had been treated with alendronate for a long time. Nineteen (76\%) of these 25 patients demonstrated a simple, transverse fracture with a unicortical beak in an area of cortical hypertrophy. This unique radiographic fracture pattern was seen in only one patient $(2 \%)$ not treated with alendronate. Alendronate use was a significant risk factor for this fracture pattern (odds ratio $=139.33,95 \%$ CI 19.0 to 939.4, $\mathrm{p}<0.0001) .{ }^{85}$ Based on the findings of Goh et $\mathrm{al}^{84}$ and their own data, Neviaser et $\mathrm{a}^{85}$ hypothesized that the unique radiographic pattern and prodromal pain suggest that the complete femoral diaphyseal fracture in bisphosphonate users may result from propagation of a stress fracture unable to heal because of the excessive bisphosphonate bone turnover sup- pression.$^{82,83}$ Kwek et al ${ }^{86}$ described a similar pattern of fracture in 17 patients on alendronate therapy who suffered low energy subtrochanteric fractures. In addition, $53 \%$ of the patients had bilateral findings of stress reactions or fractures. These authors emphasized the prodromal thigh pain or vague discomfort in $76 \%$ of these patients, a symptom which should lead to radiographic examination of the femur; in the event of a documented fracture, a radiographic examination of the contralateral femur should also be performed. ${ }^{86}$

The question as to whether low-energy subtrochanteric or proximal femoral shaft fractures are more frequent in alendronate (or any other bisphosphonate) users compared to non-users cannot be answered at present with certainty. Prospective or cross-sectional studies including large numbers of patients are needed to resolve this issue. Subtrochanteric or proximal femoral shaft fractures are not commonly encountered in patients with untreated postmenopausal osteoporosis. In a study from Finland, some specific features of the low-energy femoral shaft fractures which occurred between 1985 and 1994 were described in 50 patients. ${ }^{87}$ In this report, bisphosphonate treatment was not considered as a predisposing factor of this type of fracture and very likely no patient of this study was a bisphosphonate user. However, the majority of patients with low-energy femoral shaft fracture had one or more predisposing factors, such as diabetes mellitus, chronic corticosteroid treatment for pulmonary disease or rheumatoid arthritis, and severe osteoarthritis of the ipsilateral hip or knee. The total incidence of these fractures was 2.5 per 100,000 person-years. For people aged $15-60 y$, it was 0.8 per 100,000 person-years and for people aged $60 \mathrm{y}$ and older it was 7.8 per 100,000 person-years. The latter figure indicates that in the elderly one out of 400 fractures is a low-energy femoral shaft fracture ${ }^{87}$ The authors concluded that a typical lowenergy fracture of the femoral shaft is a closed spiral fracture with minimal comminution in the middle third of the left femur of an aged woman, with a high rate of postoperative complications. It seems that the pattern of the femoral shaft fractures in patients on long-term alendronate therapy described by Goh et $\mathrm{al}^{84}$ and Kwek et al ${ }^{86}$ is different from that of the femoral shaft fractures occurring in non-users of 
bisphosphonates. ${ }^{87}$

The study of a limited number of patients on longterm therapy with bisphosphonates who sustained fractures of the femoral diaphysis indicate that a stress fracture, with hypertrophy of the femoral cortex associated with local pain, often precedes the complete fracture by several weeks or months. ${ }^{84,86}$ Patients on long-term $(>2 y)$ treatment with bisphosphonates should be instructed that pain or discomfort in the region of the upper thigh or the groin may be prodromal of fracture of the proximal diaphysis of the femur, for which they should consult an orthopedic surgeon.

\section{Miscellaneous adverse events}

A few cases of bisphosphonate-associated cutaneous reactions have been reported, such as urticaria to alendronate ${ }^{88}$ and pamidronate..$^{89}$ Remarkably, alendronate challenge did not provoke a reaction in two of the patients with a previous urticarial reaction to pamidronate, while one patient was subsequently treated with clodronate without an untoward reaction. ${ }^{89}$ Rare cases of rash/pruritus have been reported with alendronate, risedronate and etidronate. ${ }^{90} \mathrm{Re}$ ported skin reactions to alendronate also include lichen planus, ${ }^{91}$ superficial gyrate erythema, ${ }^{92}$ papulopetechial skin eruption ${ }^{93}$ and superficial perivascular spongiotic dermatitis. ${ }^{94} \mathrm{~A}$ case of risedronate-associated cutaneous vasculitis has also been reported. ${ }^{95}$ Some cases were confirmed by a positive rechallenge test. ${ }^{89,92,94,95}$ Interestingly, one patient sensitized to alendronate tolerated treatment with risedronate. ${ }^{94}$ Thus, these cases ${ }^{89,94}$ indicate that skin reactions to bisphosphonates are not a class effect. ${ }^{94}$

Habitual immediate contact of the alendronate tablets with the oral mucosa, e.g. sucking the tablets instead of swallowing them, was the cause of contact stomatitis with oral ulcerations in several cases. ${ }^{96-100}$ In our opinion, some of these cases are remarkable in that they could be misdiagnosed as cases of osteonecrosis of the jaw and raise the question that, habitual contact of the bisphosphonate tablet with the gingival mucosa could possibly lead to osteonecrosis of the jaw.

A few cases of hepatitis developing several months $s^{101-103}$ or years ${ }^{104}$ after starting bisphosphonate therapy and resolving several months after discontinuing bisphosphonates have been reported. Liver biopsy ${ }^{101,103}$ revealed lesions suggestive of a drug effect.

In a recent letter, Wysowski ${ }^{105}$ gives an account of reports of esophageal cancer with oral bisphosphonate use. From 1995 through 2008 the FDA received reports of 23 patients in the United States with esophageal cancer, with alendronate as the suspect drug. Thirty-one patients from Europe and Japan were also reported with esophageal cancer, with alendronate as the suspect drug in 21 of the patients, risedronate, ibandronate or etidronate in six cases and bisphosphonates as concomitant drugs in four cases. The median time from alendronate use to diagnosis was 2.1 years in the USA cases and 1.3 years in the European and Japanese cases. The relatively short time from drug exposure to diagnosis seems more consistent with the drugs acting as tumor promoters rather than as tumor initiators. ${ }^{106}$ Four patients were treated with bisphosphonates for osteoporosis despite having Barrett's esophagus. Wysowski ${ }^{105}$ recommends that practitioners should avoid prescribing bisphosphonates to patients with Barrett's esophagus.

\section{CONCLUSION}

The bisphosphonates are essential in the treatment of postmenopausal osteoporosis as well as of male and secondary osteoporosis. They can reduce the risk of vertebral fracture by approximately $50 \%$ and of nonvertebral fracture, including the hip, by 20$50 \%$. The positive impact of bisphosphonates on the management of millions of patients with osteoporosis and other metabolic bone disorders has been enormous. Bisphosphonates also have a pivotal role in the treatment of patients with various malignant diseases involving bone. The overall safety and tolerability of bisphosphonate treatment for osteoporosis has been very good and any serious adverse events related to this therapy are rare. The aim of the present review is to increase the clinician's awareness of older and recently reported bisphosphonate-associated adverse events in the hope of further increasing the safety of a therapy which has been proven to be beneficial to many patients. 


\section{REFERENCES}

1. Roelofs AJ, Thompson K, Gordon S, Rogers MJ, 2006 Molecular mechanisms of action of bisphosphonates: current status. Clin Cancer Res 12: 6222s-6230s.

2. Weinstein RS, Roberston PK, Manolagas SC, 2009 Giant osteoclast formation and long-term oral bisphosphonate therapy. N Engl J Med 360: 53-62.

3. Tanvetyanon T, Stiff PJ, 2006 Management of the adverse effects associated with intravenous disphosphonates. Ann Oncol 17: 897-907.

4. de Groen PC, Lubbe DF, Hirsch LJ, et al, 1996 Esophagitis associated with the use of alendronate. N Engl J Med 335: 1016-1021.

5. Bauer DC, Black D, Ensrud K, et al, 2000 Upper gastrointestinal tract safety profile of alendronate. The fracture intervention trial. Arch Intern Med 160: 517-525.

6. Cryer B, Miller P, Petruschke RA, Chen E, Geba GP, De Papp AE, 2005 Upper gastrointestinal tolerability of once weekly alendronate $70 \mathrm{mg}$ with concomitant nonsteroidal anti-inflammatory drug use. Aliment Pharmacol Ther 21: 599-607.

7. Greenspan S, Field-Munves E, Tonino R, et al, 2002 Tolerability of once-weekly alendromate in patients with osteoporosis: a randomized, double-blind, placebo-controlled study. Mayo Clin Proc 77: 1044-1052.

8. Eisman JA, Rizzoli R, Roman-Ivorra J, et al, 2004 Upper gastrointestinal and overall tolerability of alendronate once weekly in patients with osteoporosis: results of a randomized, double-blind, placebo-contolled study. Curr Med Res Opin 20: 699-705.

9. Cryer B, Bauer DC, 2002 Oral bisphosphonates and upper gastrointestinal tract problems: what is the evidence? Mayo Clin Proc 77: 1031-1043.

10. Bobba RS, Beattie K, Parkinson B, Kumbhare D, Adachi JD, 2006 Tolerability of different dosing regimens of bisphosphonates for the treatment of osteoporosis and malignant bone disease. Drug Saf 29: 1133-1152.

11. Locke GR $3^{\text {rd }}$, Talley NJ, Fett SL, Zinsmeister AR, Melton LJ $3^{\text {rd }}$, 1997 Prevalence and clinical spectrum of gastroesophageal reflux: a population-based study in Olmsted County, Minnesota. Gastroenterology 112: 1448-1456.

12. Fleisch H, 2000 Bisphosphonates in bone disease. From the laboratory to the patient. Academic Press. San Diego, CA, pp, 32, 168.

13. Bounameaux HM, Schifferli J, Montani JP, Jung A, Chatelanat F,1983 Renal failure associated with intravenous bisphosphonates. Lancet 1: 471.

14. Rosen LS, Gordon D, Kaminski M, et al, 2003 Longterm efficacy and safety of zoledronic acid compared with pamidronate disodium in the treatment of skeletal complications in patients with advanced multiple myeloma or breast carcinoma: a randomized, double-blind, multicenter, comparative trial. Cancer 98: 1735-1744.

15. Chang JT, Green L, Beitz J, 2003 Renal failure with the use of zoledronic acid. N Engl J Med 349: 1676-1679.

16. Bergner R, Diel IJ, Henrich D, Hoffmann M, Uppenkamp M, 2006 Differences in nephrotoxicity of intravenous bisphosphonates for the treatment of malignancy-related bone disease. Onkologie 29: 534-540.

17. Perazella MA, Markowitz GS, 2008 Bisphosphonate nephrotoxicity. Kidney Int 74: 1385-1393.

18. Balla J, 2005 The issue of renal safety of zoledronic acid from a nephrologist's point of view. Oncologist 10: 306308.

19. Hillner BE, Ingle JN, Chlebowski RT, et al, 2003 American society of clinical oncology 2003 update on the role of bisphosphonates and bone health issues in women with breast cancer. J Clin Oncol 21: 4042-4057.

20. Body JJ, 2006 The risk of cumulative renal effects of intravenous bisphosphonates. Support Cancer Ther 3: 77-83.

21. Klawansky S, Komaroff E, Cavanaugh PF, et al, 2003 Relationship between age, renal function and bone mineral density in the US population. Osteoporos Int 14: 570-576.

22. Jassal SK, von Muhlen D, Barrett-Connor E, 2007 Measures of renal function, BMD, bone loss, and osteoporotic fracture in older adults: the Rancho Bernardo Study. J Bone Min Res 22: 203-210.

23. Miller PD, Roux C, Boonen S, Barton IP, Dunlap LE, Burgio DE, 2005 Safety and efficacy of risedronate in patients with age-related reduced renal function as estimated by the Cockcroft and Gaukt method: a pooled analysis of nine clinical trials. J Bone Min Res 20: 21052115.

24. Miura N, Mizuno N, Aoyama R, 2009 Massive proteinuria and acute renal failure after oral bisphosphonate (alendronate) administration in a patient with segmental glomerulosclerosis. Clin Exp Nephrol 13: 85-88.

25. Fraunfelder FW, Fraunfelder FT, Jensvold B, 2003 Scleritis and other ocular side effects associated with pamidronate disodium. Am J Ophthalmol 135: 219-222.

26. French DD, Margo CE, 2008 Postmarketing surveillance of uveitis and scleritis with bisphosphonates among a national veteran cohort. Retina 28: 889-893.

27. Benderson D, Karakunnel, Kathuria S, Badros A, 2006 Scleritis complicating zoledronic acid infusion. Clin Lymphoma Myeloma 7: 145-147.

28. El Saghir NS, Otrock ZK, Bleik JH, 2005 Unilateral anterior uveitis complicating zoledronic acid therapy in breast cancer. BMC Cancer 5: 156.

29. Kilickap S, Ozdamar Y, Altundag MK, Dizdar O, 2008 A case report: zoledronic acid -induced uveitis. Med Oncol 25: 238-240.

30. Leung S, Ashar BH, Miller RG, 2005 Bisphosphonateassocoated scleritis: a case report and review. South Med J 98: 733-735.

31. Tabbara KF, 2008 Nodular scleritis following alendronate therapy. Ocul Immunol Inflamm 16: 99-101.

32. Mbekeani JN, Slamivits TL, Schwartz BH, Sauer HL, 
1999 Ocular inflammation associated with alendronate therapy. Arch Ophthalmol 117: 837-838.

33. Malik AR, Campbell SH, Toma NMG, 2002 Bilateral acute anterior uveitis after alendronate. Br J Ophthalmol 86: 1443.

34. Fietta P, Manganelli P, Lodigiani L, 2003 Clodronate induced uveitis. Ann Rheum Dis 62: 378.

35. Aurich-Barrera B, Wilton L, Harris S, Shakir SW, 2006 Ophthalmological events in patients receiving risedronate: summary of information gained through follow-up in a prescription-event monitoring study in England. Drug Safety 29: 151-160.

36. Adami S, Bhalla AK, Dorizzi R, 1987 The acute-phase response after bisphosphonate administration. Calcif Tissue Int 41: 326-331.

37. Olson K, Van Poznak C, 2007 Significance and impact of bisphosphonate-induced acute phase responses. J Oncol Pharm Practice 13: 223-229.

38. Santini D, Vincenzi B, Caraglia M, Tonini G, 2007 A hitherto unreported high incidence of zoledronic acidinduced acute phase reaction in patients with cancer treatment-induced bone loss. Ann Oncol 18: 201-202.

39. Miller PD, McClung MR, Macovei L, et al, 2005 Monthly oral ibandronate therapy in postmenopausal osteoporosis: 1-year results from the MOBILE study. J Bone Min Res 20: 1315-1322.

40. Schweitzer DH, Oostendorp-vande Ruit M, van der Pluijm G, Lowik CWGM, Papapoulos SE, 1995 Interleukin-6 and the acute phase response during treatment of patients with Paget's disease with the nitrogen-containing bisphosphonate dimethylamonohydroxypoproylidine bisphosphonate. J Bone Min Res 10: 956-962.

41. Hewitt RE, Lissina A, Green AE, Slay ES, Price DA, Sewell AK, 2005 The bisphosphonate acute phase response: rapid and copious production of proinflammatory cytokines by peripheral blood $\gamma \delta \mathrm{T}$ cells in response to aminobisphosphonates is inhibited by statins. Clin Exp Immunol 139: 101-111.

42. Srivastava T, Haney CJ, Alon US, 2009 Atorvastatin may have no effect on acute phase reaction in children following intravenous bisphosphonate infusion. J Bone Min Res 24: 334-337.

43. Harris ST, Gertz BJ, Genant HK, et al, 1993 The effect of short term treatment with alendronate on vertebral density and biochemical markers of bone remodeling in early postmenopausal women J Clin Endocrinol Metab 76: 1399-1406.

44. Chennuru S, Koduri J, Bauman MA, 2008 Risk factors for symtomatic hypocalcemia complicating treatment with zoledronic acid. Intern Med J 38: 635-637.

45. Schussheim DH, Jacobs TP, Silverberg SJ, 1999 Hypocalcemia associated with alendronate. Ann Intern Med 130: 329 .

46. Maalouf NM, Heller HJ, Odvina CV, Kim PJ, Sakhaee K, 2006 Bisphosphonate-induced hypocalcemia: report of 3 cases and review of literature. Endocr pract 12: 48-53.
47. Richmond BK, 2005 Profound refractory hypocalcemia after thyroidectomy in a patient receiving chronic oral bisphosphonate therapy. Am Surg 71: 872-873.

48. Macisaac RJ, Seeman E, Herums G, 2002 Seizures after alendronate. J Royal Soc Med 95: 615-616.

49. Henley D, Kaye J, Walsh J, Cull G, 2005 Symptomatic hypocalcemia and renal impairment associated with bisphosphonate treatment in patients with multiple myeloma. Intern Med J 35: 726-728.

50. Berruti A, Tucci M, Generali D, et al, 2006 Management of the side-effects of intravenous bisphosphonates: targeting the serum parathyroid hormone elevation. Ann Oncol 17: 1854-1855.

51. http://www.fda.gov/cder/drug/infopage/bisphosphonates/ default.htm

52. Wysowski DK, Chang JT, 2005 Alendronate and risedronate: reports of severe bone, joint, and muscle pain. Arch Intern Med 165: 346-347.

53. Bock O, Boerst H, Thomasius FE, et al, 2007 Common musculoskeletal adverse effects of oral treatment with once weekly alendronate and risedronate in patients with osteoporosis and ways for their prevention. J Musculoskelet Neuronal Interact 7: 144-148.

54. Gwynne Jones D, Savage R, Highton J, 2005 Synovitis induced by alendronic acid can present as acute carpal tunnel syndrome. BMJ 330: 74.

55. Gwynne Jones DP, Savage RL, Highton J, 2008 Alendronate-induced synovitis. J Rheumatol 35: 537-538.

56. Gerster JC, 2004 Acute polyarthritis related to once-weekly alendronate in a woman with osteoporosis. J Rheumatol 31: $829-830$.

57. de Torrenté da la Jara G, Pécoud A, Favrat B, 2004 Musculoskeletal pain in female asylum seekers and hypovitaminosis $\mathrm{D}_{3}$. BMJ 329: 156-157.

58. Nakchbandi IA, Grey A, Masiukewicz U, Mitnick M, Insogna K 2001 Cytokines in primary hyperparathyroidism. In: Bilezikian JP, Marcus R, Levine M (eds). The Parathyroids, Basic and Clinical Concepts. Academic Press, San Diego, CA; pp, 411-421.

59. Edwards BJ, Gounder M, McKoy JM, 2008 Pharmacovigilance and reporting oversight in US FDA fast-track process: bisphosphonates and osteonecrosis of the jaw. Lancet Oncol 9: 1166-1172.

60. Marx RE, 2003 Pamidronate (Aredia) and Zoledronate (Zometa) induced avascular necrosis of the jaws: a growing epidemic. J Oral Maxillofac Surg 61: 1238-1239.

61. Ruggiero SL, Mehrotra B, Rosenberg TJ, Engroff SL, 2004 Osteonecrosis of the jaws associated with the use of bisphosphonates: a review of 63 cases. J Oral Maxillofac Surg 62: 527-534.

62. Bamias A, Kastritis E, Bamia C, 2005 Osteonecrosis of the jaw in cancer after treatment with bisphosphonates: incidence and risk factors. J Clin Oncol 23: 8580-8587.

63. Khosla S, Burr D, Cauley J, 2007 Bisphosphonate-associated osteonecrosis of the jaw: report of a task force of the American Society for Bone Na Mineral Research. 
Editorial. J Bone Min Res 22: 1479-1491.

64. Woo SB, Hellstein JW, Kalmar JR, 2006 Systematic review: bisphosphonates and osteonecrosis of the jaws. Ann Intern Med 144: 753-761.

65. Ruggiero S, Gralow J, Marx RE, 2006 Practical guidelines for the prevention, diagnosis, and treatment of osteonecrosis of the jaw in patients with cancer. J Oncol Pract 2: 7-14.

66. American Association of Oral and Maxillofacial Surgeons Position Paper on Bisphosphonate-Related Osteonecrosis of the Jaws, September 25, 2006 http://www.aaoms. org/docs/position_papers/osteonecrosis.pdf.

67. Marx RE, Cillo JE Jr, Ulloa JJ, 2007 Oral bisphosphonate-induced osteonecrosis: risk factors,prediction of risk using serum CTX testing, prevention, and treatment. J Oral Maxillofac Surg 65: 2397-2410.

68. Pazianas M, Miller P, Blumentals WA, Bernal M, Kothawala P, 2007 A review of the literature on osteonecrosis of the jaw in patients with osteoporosis treated with oral bisphosphonates: prevalence, risk factors, and clinical characteristics. Clin Ther 29: 1548-1558.

69. Rizzoli R, Burlet N, Cahall D, et al, 2008 Osteonecrosis of the jaw and bisphosphonate treatment for osteoporosis. Bone 42: 841-847.

70. Marx RE, 2008 Uncovering the cause of "phossy jaw" circa 1858 to 1906: oral and maxillofacial surgery closed case file-case closed. J Oral Maxillofac Surg 66: 23562363.

71. Ardine M, Generali D, Donadio M, 2006 Could the long-term persistence of low serum calcium levels and high serum parathyroid hormone levels during bisphosphonate treatment predispose metastatic breast cancer patients to undergo osteonecrosis of the jaw? Ann Oncol 17: 1336-1337.

72. Padbury AD Jr, Tözüm TF, Taba M Jr, et al, 2006 The impact of primary hyperparathyroidism on the oral cavity. J Clin Endocrinol Metab 91: 3439-3445.

73. Phal PM, Myall RWT, Assael LA, Weissman JL, 2007 Imaging findings of bisphosphonate-associated osteonecrosis of the jaw. Am J Neuroradiol 28: 1139-1145.

74. Black DM, Delmas PD, Eastell R, et al, 2007 Onceyearly zoledronic acid for treatment of postmenopausal osteoporosis. N Engl J Med 356: 1809-1822.

75. Cummings SR, Balck DM, Thompson DE, et al, 1998 Effect of alendronate on risk of fracture in women with low bone density but without vertebral fractures: results from the Fracture Intervention Trial. JAMA 280: 2077 2082.

76. Cummings SR, Schwatz AV, 2007 Alendronate and atrial fibrillation. N End J Med 356: 1895-1896.

77. Lyles KW, Colon-Emeric CS, Magaziner JS, et al, HORIZON Recurrent Fracture Trial, 2007 Zoledronic acid and clinical fractures and mortality after hip fracture. $\mathrm{N}$ Engl J Med 357: 1799-1809.

78. Karam R, Camm J, McKlung M, 2007 Yearly zoledronic acid in postmenopausal osteoporosis. Letter. $\mathrm{N}$ Engl $\mathrm{J}$
Med 356: 712-713.

79. Heckhert SR, Li G, Cummings SR, et al, 2008 Use of alendronate and risk of incident atrial fibrillation in women. Arch Intern Med 168: 826-831.

80. Sorensen HT, Christensen S, Mehnert F, et al, 2008 Use of bisphosphonates among women and risk of atrial fibrillation and flutter: population based case-control study. BMJ 336: 813-816.

81. http://www.fda.gov./cder/drug/early_comm/bisphosphonates_update_200811.htm

82. Odvina CV, Zerwekh JE, Rao ES, et al, 2005 Severely suppressed bone turnover: a potential complication of alendronate therapy. J Clin Endocrinol Metab 90: 12941301.

83. Visekruna M, Wilson D, McKienan FE, 2008 Severely suppressed bone turnover and atypical skeletal fragility. J Clin Endocrinol Metab 93: 2948-2952.

84. Goh SK, Yang KY, Koh JS, et al, 2007 Subtrochanteric insufficiency fractures in patients on alendronate therapy: a caution. J Bone Joint Surg (Br) 89: 349-353.

85. Neviaser AS, Lane JM, Lenart BA, Edobor-Osula F, Lorich DG, 2008 Low-enrgy femoral shaft fractures associated with alendronate use. J Orthop Trauma 22: 346-350.

86. Kwek EB, Gosh SK, Koh JS, Png MA, Howe TS, 2008 An emerging pattern of subtrochanteric stress fractures: a long-term complication of alendronate therapy? Injury 39: 234-231.

87. Salminen S, Pihlajamaki H, Avikainen V, et al, 1997 Specific features associated with femoral shaft fractures caused by low-energy trauma. J Trauma 43: 117-122.

88. Kontoleon P, Ilias I, Stavropoulos PG, Papapetrou PD, 2000 Urticaria after administration of alendronate. Acta Derm Venereol 80: 398.

89. Phillips E, Knowles S, Weber E, Shear NH, 1998 Skin reactions associated with bisphosphonates: a report of 3 cases and an approach to management. Allergy Clin Immunol 102(4 Pt): 697-698.

90. Anastasakis AD, Goulis DG, Kita M, Avramidis A, 2007 Oral bisphosphonate adverse effects in 849 patients with metabolic bone disease. Hormones (Athens) 6: 233241.

91. Lazarov A, Moss K, Plosk N, Cordova M, Baitelman L, 2002 Alendronate-induced lichen planus. IMAJ 4: 389390.

92. High WA, Cohen JB, Wetherington W, Cockerell CJ, 2003 Superficial gyrate erythema as a cutaneous reaction to alendronate for osteoporosis. J Am Acad Dermatol 48: 945-946.

93. Kimura M, Kawada A, Murayama Y, Murayama M, 2003 Drug eruption due to alendronate sodium hydrate. Contact Dermatitis 48: 116.

94. Brinkmeier T, Kügler K, Lepoittevin JP, Frosch PJ, 2007 Adverse cutaneous drug reaction to alendronate. Contact Dermatitis 57: 123-125.

95. Belhadjali H, Slim R, Aouam K, Youssef M, Zilli J, 2008 
Cutaneous vasculitis induced by risedronate. Allergy 63: 1405.

96. Demerjian N, Bolla G, Spreux A, 2000 Severe oral ulcerations induced by alendronate. Clin Rheumatol 18 : 349-350.

97. Gonzalez-Moles MA, Bagan-Sebastian JV, 2000 Alendronate-related oral mucosa ulcerations. J Oral Pathol Med 29: 514-518.

98. Krasagakis K, Krüger-Krasagakis S, Ioannidou D, Tosca A, 2004 Chronic erosive and ulcerative oral lesions caused by incorrect administration of alendronate. J Am Acad Dermatol 50: 651-652.

99. Schmutz JL, Barbaud A, Trechot P, 2005 Alendronate et ulcerations buccales: d'abord bien interroger le patient Ann Dermatol Venereol 132: 930.

100. Rubegni P, Fimiani M, 2006 Images in clinical medicine.
Bisphosphonate-associated contact stomatitis. N Engl J Med 355: e25.

101. Halabe A, Lifschitz BM, Azuri J, 2000 Liver damage due to alendronate 343: 365-366.

102. Carrére C, Duvaal JL, Godard B, De Jaureguiberry JP, Ciribilli JM, 2002 Severe acute hepatitis induced by alendronate. Gastroenterol Clin Biol 16: 179-180.

103. Yanik B, Turkay C, Atalar H, 2007 Hepatotoxicity induced by alendronate therapy. Osteoporos Int 18: 829-831.

104. Phillips MB, 2007 Risedronate-induced hepatitis. Am J Med 120: e1-2.

105. Wysowski DK, 2009 Reports of esophageal cancer with oral bisphosphonate use. N Engl J Med 360: 89-90.

106. Chustecka Z, 2009 Esophageal cancer in patients taking oral bisphosphonates. http://www.medscape.com/viewarticle/586127. 